\title{
Strength of niche processes for species interactions is lower for generalists and exotic species
}

\author{
Guadalupe Peralta ${ }^{1}$ (D) | George L. W. Perry ${ }^{2}$ (D) | Diego P. Vázquez ${ }^{3,4}$ (D) | \\ D. Matthias Dehling ${ }^{1}$ (i) | Jason M. Tylianakis ${ }^{1}$
}

${ }^{1}$ Centre for Integrative Ecology, School of Biological Sciences, University of Canterbury, Christchurch, New Zealand

${ }^{2}$ School of Environment, University of Auckland, Auckland, New Zealand

${ }^{3}$ Instituto Argentino de Investigaciones de las Zonas Áridas, CONICET, Mendoza, Argentina

${ }^{4}$ Facultad de Ciencias Exactas y Naturales, Universidad Nacional de Cuyo, Mendoza, Argentina

\section{Correspondence}

Guadalupe Peralta

Email: gdlp.peralta@gmail.com

\section{Present address}

Guadalupe Peralta, School of Biological Sciences, University of Canterbury, 20 Kirkwood Avenue, Christchurch, 8041, New Zealand

Funding information

Deutsche Forschungsgemeinschaft, Grant/ Award Number: DFG 2754/1-1; Marsden

Fund, Grant/Award Number: UOC1705

Handling Editor: Elisa Thébault

\begin{abstract}
1. Niche and neutral processes jointly influence species interactions. Predictions of interactions based on these processes assume that they operate similarly across all species. However, species characteristics could systematically create differences in the strength of niche or neutral processes for each interspecific interaction.

2. We used national-level records of plant-frugivore interactions, species traits, biogeographic status (native vs. exotic), phylogenies and species range sizes to test the hypothesis that the strength of niche processes in species interactions changes in predictable ways depending on trophic generalism and biogeographic status of the interacting species.

3. The strength of niche processes (measured as trait matching) decreased when the generalism of the interacting partners increased. Furthermore, the slope of this negative relationship between trait matching and generalism of the interacting partners was steeper (more negative) for interactions between exotic species than those between native species. These results remained significant after accounting for the potential effects of neutral processes (estimated by species range size).

4. These observed changes in the strength of niche processes in generating species interactions, after accounting for effects of neutral processes, could improve predictions of ecological networks from species trait data. Specifically, due to their shorter co-evolutionary history, exotic species tend to interact with native species even when lower trait matching occurs than in interactions among native species. Likewise, interactions between generalist bird species and generalist plant species should be expected to occur despite low trait matching between species, whereas interactions between specialist species involve higher trait matching.
\end{abstract}

\section{KEYWORDS}

birds, functional diversity, native species, neutral processes, phylogenetic matching, plantfrugivore networks, specialization, trait matching

\section{1 | INTRODUCTION}

Ecological networks depict relationships of dependence among interacting species in a community, and have been called the 'architecture of biodiversity' (Bascompte, 2009). This architecture influences the functioning (Peralta, Frost, Rand, Didham, \& Tylianakis, 2014) and, potentially, the stability of ecological communities (Rohr, Saavedra, \& Bascompte, 2014; Thébault \& Fontaine, 2010, but see Maynard, Serván, \& Allesina, 2018; Peralta, Stouffer, Bringa, \& Vázquez, 2020). Therefore, unravelling the processes that structure 
ecological networks is fundamental to understanding ecological processes in communities and hence to assess the future of biodiversity.

Niche (morphological and behavioural adaptations to the biotic and abiotic environment) and neutral (stochastic) processes have been recognized as important determinants of ecological network topology (Dormann, Fründ, \& Schaefer, 2017; Vázquez, Chacoff, \& Cagnolo, 2009; Vizentin-Bugoni, Maruyama, \& Sazima, 2014). Niche processes involve trait matching of interacting species and of species with their environments, reflecting adaptation, competition and environmental filtering, whereas neutral processes emphasize the importance of stochasticity in explaining the occurrence of species and interactions in a community. In species interaction models, niche processes are usually represented by species traits (Bartomeus, 2013; Schleuning et al., 2014) or phylogenies, as surrogates for suites of traits (Pearse \& Altermatt, 2013; Rezende, Lavabre, Guimarães, Jordano, \& Bascompte, 2007). Conversely, neutral processes make interactions more likely to occur when species co-occur frequently in space or time, and are therefore typically represented by species abundances (Vázquez et al., 2007). Although both niche and neutral processes influence species interactions, the importance of each in determining interspecific interactions is still debated (Sazatornil et al., 2016; Vázquez et al., 2009).

Studies quantifying the influence of niche processes on ecological networks, or those that predict interactions from traits (Eklöf et al., 2013; Zhang, Buckling, \& Godfray, 2009), carry an implicit and, to the best of our knowledge, so far untested assumption: that the strength of niche processes such as trait matching is consistent (or at least random) across species. However, species have different characteristics that influence their interactions and hence could systematically strengthen or weaken niche processes, and thereby obscure global patterns of trait matching in interactions. For example, generalists (i.e. species with many interaction partners) tend to have traits similar to the community average (Coux, Rader, Bartomeus, \& Tylianakis, 2016), but interact with numerous species spanning a wide range of traits. Since generalists interact with a wide range of species, we could assume that their interactions with other species are mostly influenced by the abundance of their interaction partners, rather than by trait matching (niche process). In contrast, interaction partners that specialize on each other will likely show strong evidence of niche processes (i.e. trait or phylogenetic matching), although such co-specialized interactions tend to be rare (Bascompte, Jordano, Melian, \& Olesen, 2003; Vázquez \& Aizen, 2004, but see Dehling, Jordano, Schaefer, Böhning-Gaese, \& Schleuning, 2016). In addition, in mutualistic networks, many specialist species tend to interact with generalist species (Bascompte et al., 2003; Vázquez \& Aizen, 2004). If specialists interact with generalists simply because generalists are abundant (a neutral process), rather than by specializing on them as a strategy, there could be only a weak signal, or no signal at all, of niche effects on these interactions.

Generalists continue to interact with many species when they colonize a new location, even if they have not recently co-evolved with their new partners (Emer, Memmott, Vaughan, Montoya, \& Tylianakis, 2016). Likewise, trait matching appears to break down, and neutral predictions become better supported, at the edge of biogeographical regions where distinct assemblages mix (Sazatornil et al., 2016). Finally, interactions between species that do not share a recent evolutionary history, such as those between species with different biogeographic status (i.e. natives and exotics), could blur niche processes, as exotic species tend to interact with a larger fraction of the species pool (García, Martínez, Stouffer, \& Tylianakis, 2014; Heleno, Ramos, \& Memmott, 2013). Identifying the characteristics of species for which niche processes most strongly influence interactions should improve our understanding and ability to predict the structure and dynamics of interaction networks. Specifically, knowing whether the strength of niche processes for the occurrence of interactions is different for generalist and exotic species (compared with specialist and native species) could be easily incorporated in models to predict interactions via niche relaxation, for example, by assuming the probability of generalist (and/or exotic) species to interact with species with low trait matching is higher than the probability of specialist (and/or native) species.

Here, we used an extensive database of plant-frugivore interactions published in New Zealand, species traits related to fruit consumption, species biogeographic status (native vs. exotic), phylogenies and species range size to test the hypothesis that the strength of niche processes in species interactions differs predictably across species with different characteristics. In particular, we predict that:

1. The strength of niche processes (i.e. trait and phylogenetic matching) for species interactions will decrease as the generalism of the interacting partners increases.

2. The strength of niche processes (trait and phylogenetic matching) will be weaker among interacting species of different biogeographic status (i.e. interactions between natives and exotics), as these would have had less time to co-evolve matching traits, compared with interactions between native species.

3. The relationship between the strength of niche processes (trait and phylogenetic matching) and the generalism of the interacting partners will differ according to the biogeographic status of the interacting species, such that interactions between exotic species depend less on trait matching than interactions between native species, reflecting lower adaptation and more opportunistic relationships of exotic species.

\section{2 | MATERIALS AND METHODS}

\section{1 | Metanetwork}

To test our hypotheses, we assembled a database of plant-frugivore interactions of extant taxa in New Zealand, recorded in the literature (hereafter 'metanetwork'), comprising 821 binary interactions between 47 bird and 239 plant species. This metanetwork has several strengths for testing our hypotheses. First, our well-documented set of interactions, spanning 90 studies, allowed us to determine each 
species' generalism and range of interaction partners with higher resolution than any single sampled network. Second, exotic frugivores are widespread throughout New Zealand, allowing us to test the importance of both trait matching and evolutionary history on species interactions. Finally, rare species are well represented in our dataset because their conservation interest means they are studied more often than their abundance would predict (our data capture every published occurrence of an interaction between frugivores and plants that our literature search revealed, see the Supporting Information for details on data compilation). Therefore, even though sampling effort will vary across species (as in any empirical network), our use of published data means that interactions will not be systematically more poorly resolved for rare species, as would typically occur in a single sampled network, and would thus be less likely to bias our results. However, because not all species occur everywhere and local environmental conditions can result in potential interactions not being realized (Tylianakis \& Morris, 2017), we acknowledge that this metanetwork does not represent the network that would be realized at any given location or time.

Because our metanetwork is not spatially explicit, it could be argued that some interactions could not occur simply because the species' distributions do not overlap. However, such spatial uncoupling would, if anything, mask the occurrence of niche processes by providing interaction absences when niche processes predict an interaction. Therefore, controlling for spatial uncoupling would only increase the detectability of niche processes, that is, would only strengthen the observed effects of niche processes.

\subsection{Species traits}

We selected plant and bird species traits related to fruit consumption (Dehling et al., 2014). For birds, we measured bill length (the distance from the commissural point to the tip of the closed bill), bill width (the external distance between the two commissural points) and wing pointedness, quantified with Kipp's index (calculated as the distance from the tip of the first secondary to the wing tip measured on the folded wing, divided by wing length; Eck et al., 2011). The latter influences foraging preferences (i.e. foraging in the canopy vs. the understory), while bill traits (correlated with gape size, Wheelwright, 1985) directly influence feeding behaviour by determining the maximum size of the fruit that can be consumed (Dehling et al., 2016; Muñoz, Schaefer, Böhning-Gaese, \& Schleuning, 2017). We measured all bird traits on museum specimens (see Acknowledgements), except for Melleagris gallopavo, which was measured from live specimens as it was not available in any museum. We measured four adult specimens of each species, two females and two males (except for Carduelis carduelis, for which only three female and one male specimen were available) to account for sexual dimorphism within species, and used the mean of each trait for each species for the analyses. By using the mean value of species traits, we must assume that intraspecific differences are negligible compared with interspecific variability in species traits.
The plant traits selected were fruit length, fruit diameter and plant height (as a proxy of height at which fruits are offered, Bender et al., 2018; Dehling et al., 2014). Plant traits were mostly obtained from the Ecological Traits of New Zealand Flora Database (available through the Manaaki Whenua Landcare Research managed website: https://ecotraits.landcareresearch.co.nz/) and the Flora of New Zealand (Allan, 1961, 1982), among other sources (for more details see Supporting Information). Finally, we classified all plant and bird species according to their biogeographic status into natives (including endemic and self-introduced species, that is, species that arrived to New Zealand by themselves and established breeding populations) or exotics (Ecological Traits of New Zealand Flora; New Zealand Birds Online). In our database, $30 \%$ of the bird species and $31 \%$ of the plant species were exotic. Although phenological matching has been identified as an important driver of species interactions and network architecture in plant-insect mutualistic networks (e.g. Morente-López, Lara-Romero, Ornosa, \& Iriondo, 2018; Peralta, Vázquez, et al., 2020; Vázquez et al., 2009), in plant-frugivore networks, the animal (bird) partners are typically long-lived, and although their occurrence may vary locally as they move across the landscape, their occurrence nationally (the scale of our study) is constant except for migratory species. Because none of the species in our network were migratory, we did not include phenology as a trait to test trait matching.

\section{3 | Species phylogenies}

Because phylogenies encompass information on inherited traits and evolutionary events (Peralta, 2016), they can be important predictors of species interactions; therefore, we used published ultrametric phylogenies for plants and birds. We extracted a plant phylogeny from the Phylomatic tree for plants (R20120829), using the Phylomatic v3 software (Webb \& Donoghue, 2005) and assigned branch lengths using the bladj function in Phylocom v 4.2 (Webb, Ackerly, \& Kembel, 2008), which constrains node age according to the dated molecular phylogeny of Wikström, Savolainen, and Chase (2001). We then calculated pairwise phylogenetic distances using the cophenetic.phylo function in the APE $\vee 5.1$ R package (Paradis, Claude, \& Strimmer, 2004).

We extracted the bird phylogeny from birdtree.org (Jetz, Thomas, Joy, Hartmann, \& Mooers, 2012), using the most recent high-level avian topology available, the Hackett backbone (Hackett et al., 2008), with 1,000 repetitions. We then built a consensus tree using the consensus.edges function in the PHYTOOLS $v$ 0.6-44 R package (Revell, 2012), and calculated pairwise phylogenetic distances as we did for plant species. Because 5 of 47 (10.6\%) bird species were absent from the phylogeny, we calculated their phylogenetic distances based on related species, and set the distance between them to the minimum phylogenetic distance found between any two species in the phylogenetic tree. Specifically, we used the phylogenetic distances of Callaeas cinerea for Callaeas wilsoni; of Hemiphaga novaeseelandiae for Hemiphaga novaeseelandiae chathamensis; of 
Philesturnus carunculatus for Philesturnus rufusater and of Porphyrio hochstetteri for Porphyrio melanotus, as these are the only two species in these genera. In addition, for the hybrid Cyanoramphus novaezelandiae $\times$ forbesi, we used the average phylogenetic distances between Cyanoramphus novaezelandiae and Cyanoramphus forbesi.

\section{4 | Species generalism}

We chose two metrics to quantify species generalism. First, we used a widely used metric in network studies, normalized species degree, which represents the number of interaction partners scaled by the number of possible partners (total number of species in the other level), calculated using the specieslevel function in the BIPARTITE $v 2.08 \mathrm{R}$ package (Dormann, Gruber, \& Fründ, 2008). Second, we used a functional measure of species generalism derived from a functional diversity (FD) framework. This metric, a species' contribution to functional diversity $\left(F D_{\text {base }}\right)$, represents a measure of the functional specialization of a species relative to other species in the community (Dehling et al., 2016; Dehling \& Stouffer, 2018). This functional specialization measure considers differences in species' niche sizes and niche positions, which are delimited in multivariate space by the traits of each species' interaction partners (Dehling \& Stouffer, 2018), that is, the niche of each bird species is defined by the traits of the plant species with which it interacts and vice versa. Because species contribution to $\mathrm{FD}_{\text {base }}$ increases with species functional specialization, we used 1 minus the contribution of each species to $\mathrm{FD}_{\text {base }}$ to represent functional generalism. None of the generalism metrics we used were related to variability (i.e. quantitative ranges) in the traits in our dataset (Table S1; Figure S1), nor was bird generalism positively related to bill size (Table S1; Figure S2). Nevertheless, any relationships between specific trait values (or ranges) and generalism would only weaken any evidence of niche processes, decreasing its detectability and making any findings of a niche effect more conservative.

To assess whether species generalism differed between exotic and native species, we used ANOVAs. We used bird normalized degree, bird functional generalism, plant normalized degree and plant functional generalism as response variables in different ANOVAs and exotic versus native as levels of the biogeographic status predictor variable.

\subsection{Influence of niche processes on species interactions}

To estimate the influence of niche processes on each interaction via trait matching, we used a measure of the contribution of each interaction to the overall trait matching interaction pattern of the plant and bird community (Legendre, Desdevises, \& Bazin, 2002). An interaction with a large contribution to the community trait matching pattern was deemed to indicate strong evidence of niche processes. To this end, we followed two steps. First, we calculated trait pairwise similarity for plants and birds, respectively, using Gower's similarity coefficient (Gower, 1971). There was a significant correlation between trait similarity and phylogenetic similarity matrices of plants (and birds; see Supporting Information), and we wanted to distinguish matching of measured traits (including by convergent evolution) from phylogenetic matching (potentially via other unmeasured traits and shared evolutionary history). Therefore, we removed the phylogenetic signal from the trait similarity matrices using the method of Bastazini et al. (2017). This method builds a linear model with plant (or bird) trait similarity as the response variable and plant (or bird) phylogenetic similarity (i.e. phylogenetic distances) as the predictor variable. The residuals of this model were used as the similarity (distance) between species described by their traits with phylogenetic effects removed (hereafter 'trait similarity matrix').

Second, we performed a Parafit test (Legendre et al., 2002) with the plant and bird trait similarity matrices and the species interaction matrix (metanetwork), using the parafit function from the APE $v 5.1 \mathrm{R}$ package (Paradis et al., 2004). The Parafit test is a fourth-corner analysis (Legendre, Galzin, \& Harmelin-Viven, 1997) that measures the relationship between two distance matrices through the link provided by species interaction data. In particular, Parafit quantifies the congruence between two given topologies, in this case defined by species similarity according to their morphological traits, and tests the null hypothesis that species interact randomly with respect to the trait differences at each trophic level (i.e. that bird species with similar traits do not interact with plant species with similar traits more often than expected at random). Given significant congruence (i.e. that bird species with similar traits interact with plant species with similar traits), the contribution of each interaction to this overall congruence pattern can be tested. The contribution of each interaction to the congruence pattern (statistic ParafitLink1) represents a measure of the strength of niche processes (i.e. trait matching) on each interaction.

To estimate the strength of niche processes arising from other unmeasured traits and shared evolutionary history, we repeated the previous analysis using phylogenetic distances instead of trait similarities. To this end, we performed a Parafit test using the plant and bird phylogenetic distance matrices and the species interaction matrix (metanetwork) to obtain the contribution of each interaction to the pattern of phylogenetic congruence. In this case, a significant phylogenetic congruence pattern of the overall plant-bird community indicates that closely related plant species interact with closely related bird species, and interactions with a strong contribution to this pattern are strongly affected by niche processes (i.e. phylogenetic matching).

\subsection{Effects of neutral processes on species interactions}

Our hypotheses focus on niche processes structuring interactions; however, the strength of neutral processes could covary with generalism and biogeographic status, and hence controlling for the effects of neutral processes is essential. Although species abundance is the most commonly used variable to account for neutral processes, it can be difficult to obtain, especially for a database compiled over a large spatial 
and temporal extent, like the one used here. Nevertheless, species abundance is positively related to species range size (Gaston, 1996; Köckemann, Buschmann, \& Leuschner, 2009; Lawton, 1993; Newton, 1997) and, although the mechanisms behind this relationship are not clearly understood (Borregaard \& Rahbek, 2010; Brown, 1984; Brown, Mehlman, \& Stevens, 1995), it is possible to assume that species with larger ranges also have higher abundances. Therefore, species range size (even a coarse estimate of species abundance) represents the best proxy of neutral effects available for our database.

To account for the effects of neutral processes on species interactions (as a covariate in our analyses, described below), we used the normalized number of occurrences of each species recorded in national field surveys as a measure of species range size (also correlated with species abundances, Figure S3). In particular, for bird species range size we used the most comprehensive survey of New Zealand's avifauna, the Atlas of bird distribution in New Zealand (Bull, Gaze, \& Robertson, 1985; Robertson, Hyvönen, Fraser, \& Pickard, 2007), which summarizes bird records across $96 \%$ of the country's area between 1969-1979 and 1999-2004. Specifically, we added the number of field records of each bird species recorded in $3,528(9,144 \mathrm{~m} \times 9,144 \mathrm{~m})$ and 3,542 (10,000 $\mathrm{m} \times 10,000 \mathrm{~m})$ plots, between 1969-1979 and 1999-2004, respectively, and normalized them by dividing them by the maximum number of occurrences recorded for any species. Similarly, as an estimate of plant range size, we used the number of occurrences of each plant species (i.e. the number of plots in which each species was found) recorded in the National Biodiversity Monitoring and Reporting System survey (2011-2014) divided by the maximum number of occurrences recorded for any species. This survey was designed to collect comprehensive information about New Zealand land cover vegetation by systematically sampling $20 \mathrm{~m} \times 20 \mathrm{~m}$ plots across the country (see Supporting Information for more details). For simplicity, we refer to these estimates as bird and plant species range size.

\subsection{Analyses}

To evaluate whether the strength of niche processes in determining interactions, either via trait or phylogenetic matching, varies with interacting species' generalism or species biogeographic status (native vs. exotic), we used four linear mixed models. For the first two models, the response variable was the trait matching for each interaction (i.e. the contribution of each interaction to the community trait-matching congruence pattern). Both models included biogeographic-status matching as a predictor variable. Biogeographic-status matching was considered as a three-level factor, depending on whether the plant and bird species interacting were both natives (native-native), with different biogeographic status (native-exotic) or both exotics (exotic-exotic, although not necessarily from the same origin). The other predictor variable was a measure of generalism; in the first model this predictor was the mean of the normalized degree of the interacting plant and bird species, whereas in the second model, we used the mean functional generalism of the interacting species. To assess whether the generalism of either plants or birds more strongly influenced the trait matching strength of species interactions, we ran a separate set of models using separate plant and bird generalism values rather than their mean for the interactions (Tables S2 and S3). In the third and fourth models, we used the phylogenetic matching of each interaction (i.e. the contribution of each interaction to the phylogenetic congruence pattern of the community) as the response variable, with the same predictor variables as the first and second models. Although it is possible that exotic species originated in the same location and therefore have a shared co-evolutionary history, distinguishing between interactions between exotic species with the same versus different native ranges did not affect our primary conclusions (see Table S4). [Correction added on 30 June 2020, after first online publication: wording changed from 'depending on and bird species' to 'depending on whether the plant and bird species'.]

Because species generalism can be related to neutral processes, whereby common species have a higher chance of interacting with more species and hence show a higher level of generalism (Fort, Vázquez, \& Lan, 2016; Vázquez, Poulin, Krasnov, \& Shenbrot, 2005), we incorporated the mean number of species occurrences of the two interacting species (i.e. mean range size) as a covariate in all models. We also included an interaction term in all models between mean generalism and biogeographic-status matching, to account for potential differences in the effects of generalism between species with the same biogeographic status versus species with different biogeographic status. This interaction term provides information on differences in slope of the trait matching-generalism relationship between interactions that occur between species of different biogeographicstatus matching groups. In addition, to account for the dependence among interactions sharing at least one partner, we included plant and bird species identities as random factors in all models.

All models were simplified by removing interaction terms and then main effects until no further reduction in residual deviance, measured by the akaike information criterion (AIC), was achieved (Burnham \& Anderson, 2002). Normality and homoscedasticity assumptions were visually checked (by using Normal Q-Q plot and scatterplot of residuals vs. predicted values, respectively) and met in all cases. In addition, to assess multicollinearity among predictors, we calculated the variance inflation factor (VIF) of each predictor in each model using the vif function in the CAR $v$ 3.0-2 $\mathrm{R}$ package (Fox \& Weisberg, 2011); all predictors in all models had a VIF close to 1 , indicating no severe collinearity (Zuur, leno, \& Elphick, 2010). Finally, because sampling effort was not uniform across species, we evaluated the robustness of our results to potential sampling effects by systematically removing species (Supporting Information). To this end, we removed species sequentially from those with large to small range sizes (and vice versa, from small to large range sizes), reran the analyses after each removal, and estimated the robustness of our results by calculating the percentage of species that need to be removed from the analyses for the results to change significantly (i.e. for the results to change their significance). We used the Imer function from the LMERTEST v 3.1-1 (Kuznetsova, Brockhoff, \& Christensen, 2017) R package to perform the linear mixed effects 
models. All analyses were performed in the $\mathrm{R} 3.4 .4$ environment (R Core Team, 2019).

\section{3 | RESULTS}

Overall, morphologically similar bird species tended to interact with morphologically similar plant species (significant Parafit congruence pattern $p<0.001$ ), and closely related bird species tended to interact with closely related plant species (phylogenetic Parafit congruence pattern $p<0.001$ ). The mean number of bird species each plant species interacted with (i.e. generalism) was $3.430 \pm 0.200(M \pm S E)$ and the maximum number of interaction partners for a plant species was 16 (Pseudopanax arboreus and Coprosma robusta had the highest generalism among plant species). Bird species had a higher mean $(M \pm S E=17.468 \pm 3.875)$ and maximum (105, Hemiphaga novaeseelandiae) number of interaction partners than plants. In addition, the range (i.e. variability) of plant functional generalism was 12.5 times lower (min-max $=0.993-0.997$ ) than that of birds (min$\max =0.941-0.991$ ). Therefore, plant species tended to be more specialized than birds in terms of the number of bird species with which they interacted, but more generalized in terms of bird traits.

Trait matching for each interaction significantly decreased with increasing mean generalism (i.e. degree; $t=-5.349, p<0.001$; Figure 1a), even after accounting for the effects of range size on species interactions (Table S2). Furthermore, the slope of this relationship was significantly steeper (i.e. more negative) for interactions between exotic species (exotic-exotic) than interactions between native species (native-native; biogeographic-status matching $\times$ mean generalism degree interaction: $t=-3.490, p<0.001$; Figure 1a; Table S2). Species generalism and biogeographic-status matching (i.e. the fixed effects in this model) accounted for almost $20 \%$ of the total variance (Marginal $R^{2}=0.196$, Conditional $R^{2}=0.503$ ). Similarly, the slope of the relationship between trait matching and mean functional generalism was also steeper (more negative) for interactions between exotic species (exotic-exotic) than interactions between native species (native-native; biogeographic-status matching $\times$ mean functional generalism interaction: $t=-2.464, p=0.014$; Figure 1b; Table S2). In addition, the slope of this relationship was steeper (more negative) for interactions between native and exotic species (native-exotic) than interactions between native species (native-native; $t=-2.400, p=0.017$; Figure $1 \mathrm{~b}$; Table S2). The fixed effects in this model accounted for almost $10 \%$ of the total variance (Marginal $R^{2}=0.088$, Conditional $R^{2}=0.469$ ).

On the other hand, the phylogenetic matching of interactions was not affected by mean generalism (mean normalized degree), such that this variable was not retained in the best fitting model, nor was species range size statistically significant when species generalism was excluded from the model $(t=1.371, p=0.177$; Table S2). Nevertheless, the phylogenetic matching of each interaction increased slightly with increasing species range size $(t=2.009$, $p=0.049$; Figure 2a) and significantly decreased with increasing mean functional generalism of the interacting species $(t=-2.035$, $p=0.044$; Figure $2 \mathrm{~b}$; Table S2). Fixed effects in both models of phylogenetic matching explained a low proportion of the total variance (model with mean generalism: Marginal $R^{2}=0.005$, Conditional $R^{2}=0.345 ;$ model with mean functional generalism: Marginal $R^{2}=0.012$, Conditional $R^{2}=0.341$. (a)

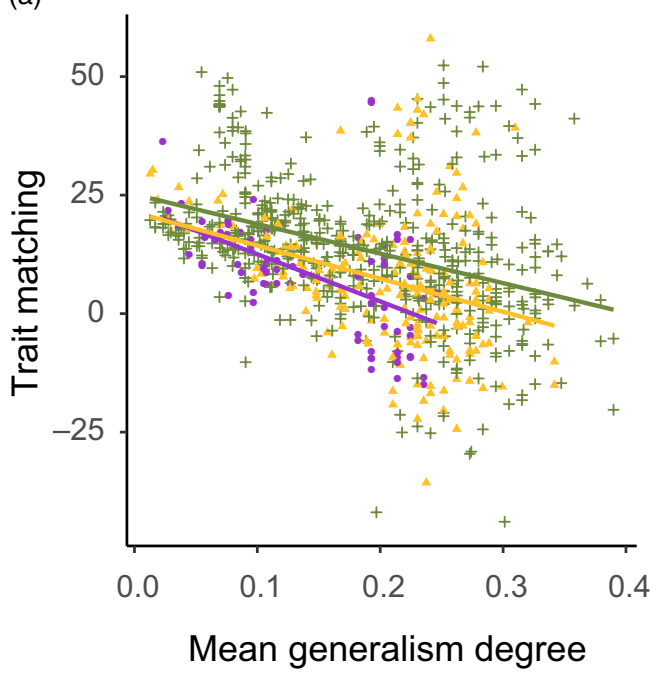

(b)

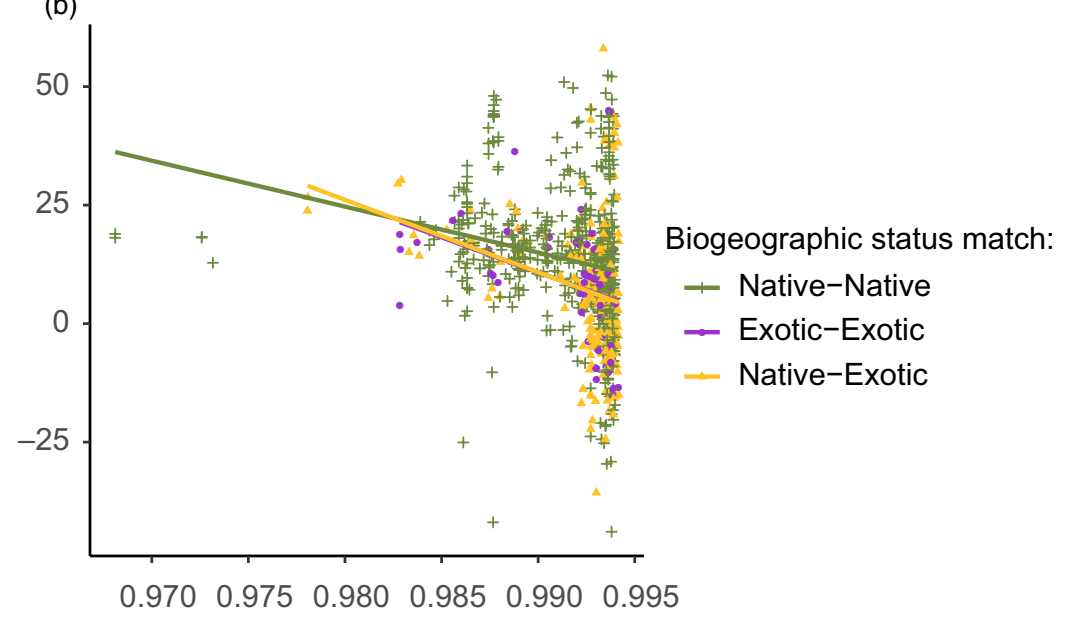

Mean functional generalism

FIGURE 1 Relationships between trait matching and characteristics of the interacting species: (a) mean degree (number of interaction partners), and (b) mean functional generalism. Symbols indicate the biogeographic-status match of the interacting species. $N=533$ (nativenative interactions), 214 (native-exotic interactions), 74 (exotic-exotic interactions). Mean functional generalism values were high, although variation within them was low (0.970-0.995), suggesting overall low functional specialization ( 0.970 corresponds to $5.9 \%$ contribution to functional diversity (FD), which represents a low specialization value, whereas 0.995 corresponds to $6.1 \%$ ). Although a linear mixed-effects model was used to evaluate changes in the trait matching-generalism relationship, least squares trend lines are shown to illustrate the direction of the relationships. Note that exotic-exotic and native-exotic trend lines overlap in (b) 
(a)

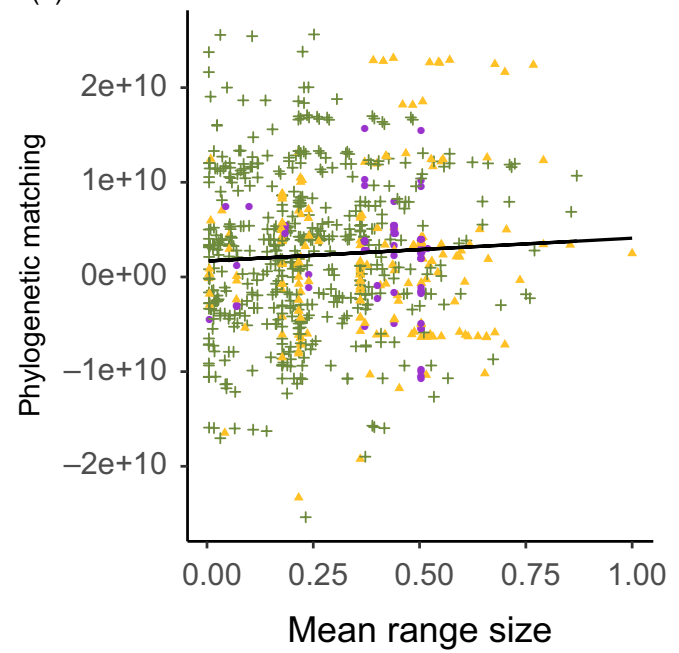

(b)

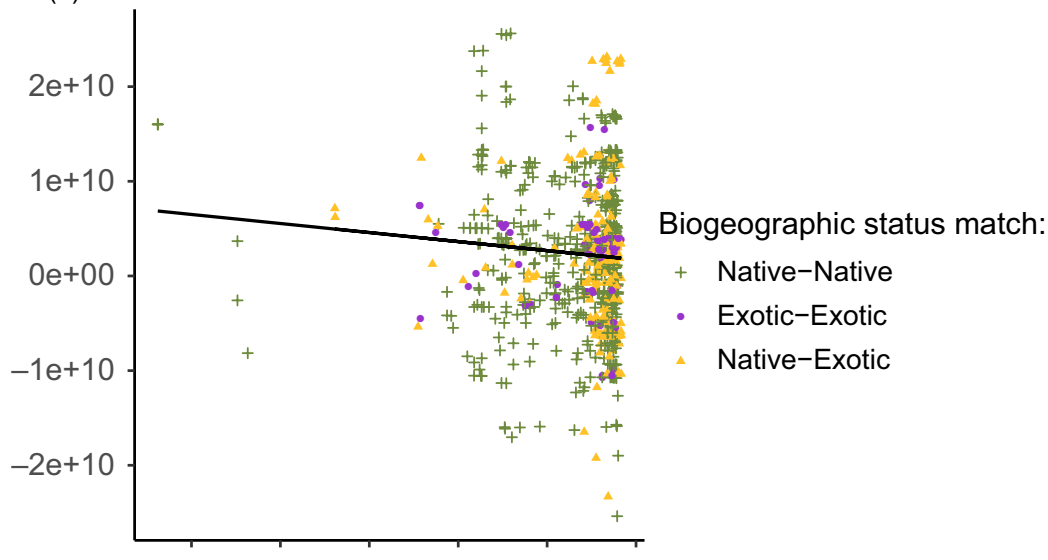

Mean functional generalism

FIGURE 2 Relationships between phylogenetic matching and characteristics of the interacting species: (a) mean range size and (b) mean functional generalism. Symbols indicate the biogeographic-status match of the interacting species

The effects of species generalism on the strength of niche processes (trait and phylogenetic matching) were mostly driven by bird generalism (both degree and functional generalism; Table S3). Despite differences in the slope of the trait matching-bird generalism relationship between species from different biogeographic statuses, we found no differences in bird generalism between native and exotic species, and only the functional generalism of plants was significantly higher for native than exotic species (Table S5).

Sensitivity analyses showed that results related to phylogenetic matching were less robust to sampling than those of trait matching. In particular, removing, on average, $7.25 \%$ of species made the phylogenetic matching-functional generalism relationship statistically non-significant, whereas $48.25 \%$ of species, on average, needed to be removed for the trait matching-mean generalism (normalized degree) relationship to become non-significant (Supporting Information, Figure S4).

\section{4 | DISCUSSION}

Niche processes are important for structuring species interactions, and the analyses of our national-level dataset are congruent with previous studies showing signals of trait (Bender et al., 2018; Eklöf et al., 2013; González-Castro, Yang, Nogales, \& Carlo, 2015; Schleuning et al., 2014; Vizentin-Bugoni et al., 2014) and phylogenetic (Martín González et al., 2015; Rezende et al., 2007) matching in the occurrence of mutualistic interactions. However, our results show that the strength of niche processes in generating species interactions changes in predictable ways depending on the species' characteristics. In particular, trait matching of the interacting partners tended to decrease when the generalism of the interacting partners increased. This negative relationship between trait matching and generalism of the interacting partners was stronger (i.e. more negative slope) for interactions between exotic species than those between native species, and it was consistent whether generalism was measured as the number of interacting partners or using a functional measure of generalism. In addition, these effects were statistically significant even after accounting for the potential covariate effects of species range size, that is, neutral processes. Our results suggest that current approaches for predicting interactions based on niche processes, such as trait matching, have limited predictive power because they assume that these processes are equally relevant for all species. We demonstrate that this assumption may not be valid, and that allowing generalist and exotic species to be differentially influenced by niche processes could improve future predictions of species interactions. Specifically, exotic species interacting with native species should be expected to interact even when lower trait matching occurs, reflecting the shorter co-evolutionary history and trait adaptation between exotic and native species. Likewise, interactions between generalist birds and generalist plants should be expected to occur despite low trait matching between species, as opposed to interactions occurring between specialist species.

Interactions between native species showed stronger trait matching than interactions between exotic species and between natives and exotics. This difference could be explained by the native species' shared evolutionary history, which allows them to co-evolve at least in the specific traits related to fruit consumption. Similarly, higher consistency in partner choice (i.e. higher partner fidelity), which is necessary for mutual adaptation in evolutionary time, has been shown for native flower visitors in the Galapagos Islands (Trøjelsgaard, Heleno, \& Traveset, 2019). In addition, the slope of the trait matchinggeneralism relationship was slightly steeper (more negative) for interactions between exotic species with different native ranges than for interactions between exotic species that shared the same native range (Table S4). It is possible that stronger signals of coevolution among exotic species sharing the same geographic origin could be detected when using higher resolution data on species native ranges. 
Phylogenetic matching slightly decreased only when species functional generalism increased, and there was no apparent difference in the slope of this relationship when comparing interactions between native species with interactions among exotic species or interactions between native and exotic species. These weaker changes in phylogenetic matching do not imply that evolution is unimportant for ecological patterns, since traits are evolutionary products, but rather that phylogenetic relationships, estimated from published phylogenies, do not capture the specific differences in interaction-relevant traits that the measured traits do (Cadotte \& Davies, 2016). Moreover, because we used measures of trait dissimilarity that removed variance associated with phylogenetic distance (Bastazini et al., 2017), we eliminated the possibility that our observed trait effects were caused by unmeasured, phylogenetically correlated traits.

Our results show that exotic species interacting with native species have lower trait matching than interactions between native species. This result has important implications given that many decisions about exotic species importation are informed by the species interactions of morphologically similar native species; however, exotic species could be less dependent on trait matching and hence interact with a broader range of species in the new location. Nevertheless, beyond the occurrence of interactions per se, the strength of exotic species interactions in a new environment is a key determinant of their impacts (Ortega \& Pearson, 2005). Niche processes are most likely to determine the range of possible versus impossible (i.e. 'forbidden links') interactions, whereas the strength of possible interactions can be modified by the local environment and relative abundance of the interaction participants (Tylianakis \& Morris, 2017). Future studies assessing potential relationships between niche processes and species interaction strengths could be extremely useful for understanding the extent to which niche processes affect communities and functions (Godoy, Bartomeus, Rohr, \& Saavedra, 2018).

Our results must be considered in the context of the specific interaction (frugivory) we studied. Frugivory networks are frequently more generalized than other types of mutualistic networks, such as pollination networks (Blüthgen, Menzel, Hovestadt, Fiala, \& Blüthgen, 2007), meaning frugivory networks may show weaker signals of trait matching than other types of interaction. In addition, although the interactions reported here represent trophic consumption from the birds' perspective, whether they constitute antagonistic or mutualistic interactions depends on whether consumed seeds are destroyed or dispersed, respectively (Simmons et al., 2018). Because mutualistic interactions could differ in their degree of trait matching compared to antagonistic interactions, this mixing of mutualistic and antagonistic frugivory could introduce noise in the analyses and weaken any trait matching signal. Finally, an obvious mechanism through which generalists may exhibit weaker trait matching would be if birds with larger bills could consume a greater range of fruit size (Moran \& Catterall, 2010; Palacio, Valderrama-Ardila, \& Kattan, 2016) and showed no preference for fruits of any particular size. This lack of selectivity would result in these larger-billed birds showing both weaker trait matching and higher generalism. Despite the plausibility of this mechanism, we observed no positive relationship between bill size (length or width) and bird generalism (Table S1; Figure S2), in contrast to previous studies (Moran \& Catterall, 2010; Palacio et al., 2016). This lack of relationship suggests that, in our study system, birds with larger bills, that is, with potentially wider ranges of suitable partners, show strong preferences for certain plant species.

To understand how networks of ecological interactions will respond to changes in the environment and to be able to predict which species in a community will interact, it is imperative to understand what drives species interactions. Here, we show that the strength of niche processes in generating species interactions depends on characteristics of the interacting species such as generalism and biogeographic-status matching. These relationships could be used to improve models that predict species interactions using traits or phylogenetic relationships (Bartomeus et al., 2016; Gravel et al., 2018; Pearse \& Altermatt, 2013). Nevertheless, it remains unknown whether the strength of niche processes in species interactions can also inform us about the strength of species interactions, an essential feature to understand the balance of interactions in a community (Godoy et al., 2018). Understanding variability in the strength of niche and neutral processes for species interactions will allow us to predict changes in species interactions and novel interactions in an increasingly changing world.

\section{ACKNOWLEDGEMENTS}

We thank Matthew Shaw and the Canterbury Museum, and Tom Schultz from the Te Papa Museum for access to the bird collections; Margaret Watts for facilitating plant traits of the Ecological Traits of New Zealand Flora database; Pieter Pelser for facilitating access to the University of Canterbury Herbarium; Jamie Wood, Kiran Parmar, and Riki Taylor for their contribution to the metanetwork database compilation. We acknowledge the use of species occurrence data drawn from the National Vegetation Survey Database (NVS) and bird biogeographic status from New Zealand Birds Online. We thank the editor and two anonymous reviewers for helpful suggestions to improve the manuscript. Symbols used in the graphical abstract are courtesy of the Integration and Application Network, University of Maryland Center for Environmental Science, ian.umces.edu/symbols/. This work was funded by the Marsden Fund (grant number UOC1705), administered by the Royal Society of New Zealand. D.M.D. was supported by a grant from the German Research Foundation (DFG 2754/1-1). The authors declare no conflict of interests.

\section{AUTHORS' CONTRIBUTIONS}

J.M.T., D.P.V., G.L.W.P. conceived the idea and secured funding; G.L.W.P. and G.P. compiled the data; G.P. performed analyses and wrote the first draft of the manuscript; M.D. contributed functional generalism code. All authors contributed substantially to revisions.

\section{DATA AVAILABILITY STATEMENT}

Data available from figshare: https://doi.org/10.17608/k6.auckl and.12367685.v2 (Perry \& Peralta, 2020). 


\section{ORCID}

Guadalupe Peralta iD https://orcid.org/0000-0003-1947-4989

George L. W. Perry (D) https://orcid.org/0000-0001-9672-9135

Diego P. Vázquez (iD https://orcid.org/0000-0002-3449-5748

D. Matthias Dehling (iD https://orcid.org/0000-0002-2863-5580

Jason M. Tylianakis (iD https://orcid.org/0000-0001-7402-5620

\section{REFERENCES}

Allan, H. H. (1961). Flora of New Zealand. Wellington, New Zealand: Government Printer Publications.

Allan, H. H. (1982). Flora of New Zealand. Wellington, New Zealand: Goverment Printer.

Bartomeus, I. (2013). Understanding linkage rules in plant-pollinator networks by using hierarchical models that incorporate pollinator detectability and plant traits. PLoS ONE, 8(7), e69200. https://doi. org/10.1371/journal.pone.0069200

Bartomeus, I., Gravel, D., Tylianakis, J. M., Aizen, M. A., Dickie, I. A., $\&$ Bernard-Verdier, M. (2016). A common framework for identifying linkage rules across different types of interactions. Functional Ecology, 30(12), 1894-1903. https://doi.org/10.1111/1365-2435. 12666

Bascompte, J. (2009). Disentangling the web of life. Science, 325(5939), 416-419. https://doi.org/10.1126/science.1170749

Bascompte, J., Jordano, P., Melian, C. J., \& Olesen, J. M. 2003). The nested assembly of plant-animal mutualistic networks. Proceedings of the National Academy of Sciences of the United States of America, 100(16), 9383-9387. https://doi.org/10.1073/pnas.1633576100

Bastazini, V. A. G., Ferreira, P. M. A., Azambuja, B. O., Casas, G., Debastiani, V. J., Guimarães, P. R., \& Pillar, V. D. (2017). Untangling the tangled bank: A novel method for partitioning the effects of phylogenies and traits on ecological networks. Evolutionary Biology, 44(3), 312-324. https://doi.org/10.1007/s11692-017-9409-8

Bender, I. M. A., Kissling, W. D., Blendinger, P. G., Böhning-Gaese, K., Hensen, I., Kühn, I., ... Schleuning, M. (2018). Morphological trait matching shapes plant-frugivore networks across the Andes. Ecography, 41(11), 1910-1919. https://doi.org/10.1111/ecog.03396

Blüthgen, N., Menzel, F., Hovestadt, T., Fiala, B., \& Blüthgen, N. (2007). Specialization, constraints, and conflicting interests in mutualistic networks. Current Biology, 17(4), 341-346. https://doi.org/10.1016/j. cub.2006.12.039

Borregaard, M. K., \& Rahbek, C. (2010). Causality of the relationship between geographic distribution and species abundance. The Quarterly Review of Biology, 85(1), 3-25. https://doi.org/10.1086/650265

Brown, J. H. (1984). On the relationship between abundance and distribution of species. The American Naturalist, 124(2), 255-279. https:// doi.org/10.1086/284267

Brown, J. H., Mehlman, D. W., \& Stevens, G. C. (1995). Spatial variation in abundance. Ecology, 76, 2028-2043. https://doi.org/10.2307/ 1941678

Bull, P. C., Gaze, P. D., \& Robertson, C. J. R. (1985). The atlas of bird distribution in New Zealand. Wellington, New Zealand: The Ornithological Society of New Zealand.

Burnham, K. P., \& Anderson, D. R. (2002). Model selection and multimodel inference: A practical information-theoretic approach (2nd ed.). New York, NY: Springer.

Cadotte, M. W., \& Davies, T. J. (2016). Phylogenies in ecology: A guide to concepts and methods. Princeton, NJ: Princeton University Press.

Coux, C., Rader, R., Bartomeus, I., \& Tylianakis, J. M. (2016). Linking species functional roles to their network roles. Ecology Letters, 19(7), 762-770. https://doi.org/10.1111/ele.12612

Dehling, D. M., Jordano, P., Schaefer, H. M., Böhning-Gaese, K., \& Schleuning, M. (2016). Morphology predicts species' functional roles and their degree of specialization in plant-frugivore interactions.
Proceedings of the Royal Society B: Biological Sciences, 283(1823), https://doi.org/10.1098/rspb.2015.2444

Dehling, D. M., \& Stouffer, D. B. (2018). Bringing the Eltonian niche into functional diversity. Oikos, 127(12), 1711-1723. https://doi. org/10.1111/oik.05415

Dehling, D. M., Töpfer, T., Schaefer, H. M., Jordano, P., Böhning-Gaese, K., \& Schleuning, M. (2014). Functional relationships beyond species richness patterns: Trait matching in plant-bird mutualisms across scales. Global Ecology and Biogeography, 23(10), 1085-1093. https:// doi.org/10.1111/geb.12193

Dormann, C. F., Fründ, J., \& Schaefer, H. M. (2017). Identifying causes of patterns in ecological networks: Opportunities and limitations. Annual Review of Ecology, Evolution, and Systematics, 48(1), 559-584. https://doi.org/10.1146/annurev-ecolsys-110316-022928

Dormann, C. F., Gruber, B., \& Fründ, J. (2008). Introducing the bipartite package: Analysing ecological networks. R News, 8(2), 8-11.

Eck, S., Fiebig, J., Fiedler, W., Heynen, I., Nicolai, B., Topfer, T., ... Woog, F. (2011). Measuring Birds - Vögel Vermessen. Deutsche Ornithologen-Gesellschaft.

Ecological Traits of New Zealand Flora. Manaaki Whenua Landcare Research managed website. Retrieved from https://ecotraits.landc areresearch.co.nz/

Eklöf, A., Jacob, U., Kopp, J., Bosch, J., Castro-Urgal, R., Chacoff, N. P., ... Allesina, S. (2013). The dimensionality of ecological networks. Ecology Letters, 16(5), 577-583. https://doi.org/10.1111/ele.12081

Emer, C., Memmott, J., Vaughan, I. P., Montoya, D., \& Tylianakis, J. M. (2016). Species roles in plant-pollinator communities are conserved across native and alien ranges. Diversity and Distributions, 22(8), 841852. https://doi.org/10.1111/ddi.12458

Fort, H., Vázquez, D. P., \& Lan, B. L. (2016). Abundance and generalisation in mutualistic networks: Solving the chicken-and-egg dilemma. Ecology Letters, 19(1), 4-11. https://doi.org/10.1111/ele.12535

Fox, J., \& Weisberg, S. (2011). An R companion to applied regression (2nd ed.). Retrieved from http://socserv.socsci.mcmaster.ca/jfox/Books/ Companion

García, D., Martínez, D., Stouffer, D. B., \& Tylianakis, J. M. (2014). Exotic birds increase generalization and compensate for native bird decline in plant-frugivore assemblages. Journal of Animal Ecology, 83(6), 1441-1450. https://doi.org/10.1111/1365-2656.12237

Gaston, K. J. (1996). Species-range-size distributions: Patterns, mechanisms and implications. Trends in Ecology \& Evolution, 11(5), 197-200. https://doi.org/10.1016/0169-5347(96)10027-6

Godoy, O., Bartomeus, I., Rohr, R. P., \& Saavedra, S. (2018). Towards the integration of niche and network theories. Trends in Ecology \& Evolution, 33(4), 287-300. https://doi.org/10.1016/j.tree.2018.01.007

González-Castro, A., Yang, S., Nogales, A., \& Carlo, T. A. (2015). Relative importance of phenotypic trait matching and species' abundances in determining plant-avian seed dispersal interactions in a small insular community. AoB Plants, 7. https://doi.org/10.1093/aobpla/plv017

Gower, J. C. (1971). A general coefficient of similarity and some of its properties. Biometrics, 27(4), 857-871. https://doi.org/10.2307/2528823

Gravel, D., Baiser, B., Dunne, J. A., Kopelke, J.-P., Martinez, N. D., Nyman, T., ... Roslin, T. (2018). Bringing Elton and Grinnell together: A quantitative framework to represent the biogeography of ecological interaction networks. Ecography. https://doi.org/10.1111/ecog.04006

Hackett, S. J., Kimball, R. T., Reddy, S., Bowie, R. C. K., Braun, E. L., Braun, M. J., ... Yuri, T. (2008). A phylogenomic study of birds reveals their evolutionary history. Science, 320(5884), 1763. https://doi. org/10.1126/science.1157704

Heleno, R. H., Ramos, J. A., \& Memmott, J. (2013). Integration of exotic seeds into an Azorean seed dispersal network. Biological Invasions, 15(5), 1143-1154. https://doi.org/10.1007/s10530-012-0357-z

Jetz, W., Thomas, G. H., Joy, J. B., Hartmann, K., \& Mooers, A. O. (2012). The global diversity of birds in space and time. Nature, 491, 444. https://doi.org/10.1038/nature11631 
Köckemann, B., Buschmann, H., \& Leuschner, C. (2009). The relationships between abundance, range size and niche breadth in Central European tree species. Journal of Biogeography, 36(5), 854-864. https://doi.org/10.1111/j.1365-2699.2008.02022.x

Kuznetsova, A., Brockhoff, P. B., \& Christensen, R. H. B. (2017). ImerTest package: Tests in linear mixed effects models. Journal of Statistical Software, 82(13), 1-26.

Lawton, J. H. (1993). Range, population abundance and conservation. Trends in Ecology \& Evolution, 8(11), 409-413. https://doi org/10.1016/0169-5347(93)90043-O

Legendre, P., Desdevises, Y., \& Bazin, E. (2002). A statistical test for host-parasite coevolution. Systematic Biology, 51, 217-234. https:// doi.org/10.1080/10635150252899734

Legendre, P., Galzin, R., \& Harmelin-Viven, M. L. (1997). Relating behavior to habitat: Solutions to the fourth-corner problem. Ecology, 78(2), 547-562. https://doi.org/10.2307/2266029

Martín González, A. M., Dalsgaard, B. O., Nogués-Bravo, D., Graham, C. H., Schleuning, M., Maruyama, P. K., ... Martinez, N. D. (2015). The macroecology of phylogenetically structured hummingbird-plant networks. Global Ecology and Biogeography, 24(11), 1212-1224. https:// doi.org/10.1111/geb.12355

Maynard, D. S., Serván, C. A., \& Allesina, S. (2018). Network spandrels reflect ecological assembly. Ecology Letters, 21(3), 324-334. https:// doi.org/10.1111/ele.12912

Moran, C., \& Catterall, C. P. (2010). Can functional traits predict ecological interactions? A case study using rain forest frugivores and plants in Australia. Biotropica, 42(3), 318-326. https://doi. org/10.1111/j.1744-7429.2009.00594.x

Morente-López, J., Lara-Romero, C., Ornosa, C., \& Iriondo, J. M. (2018). Phenology drives species interactions and modularity in a plantflower visitor network. Scientific Reports, 8, 9386. https://doi. org/10.1038/s41598-018-27725-2

Muñoz, M. C., Schaefer, H. M., Böhning-Gaese, K., \& Schleuning, M. (2017). Importance of animal and plant traits for fruit removal and seedling recruitment in a tropical forest. Oikos, 126(6), 823-832. https://doi.org/10.1111/oik.03547

New Zealand Birds Online. The digital encyclopaedia of New Zealand birds. Retrieved from http://nzbirdsonline.org.nz/

Newton, I. (1997). Links between the abundance and distribution of birds. Ecography, 20, 137-145. https://doi.org/10.1111/j.1600-0587.1997. tb00356.x

Ortega, Y. K., \& Pearson, D. E. (2005). Weak vs. strong invaders of natural plant communities: Assessing invasibility and impact. Ecological Applications, 15(2), 651-661.

Palacio, R. D., Valderrama-Ardila, C., \& Kattan, G. H. (2016). Generalist species have a central role in a highly diverse plant-frugivore network. Biotropica, 48(3), 349-355. https://doi.org/10.1111/btp. 12290

Paradis, E., Claude, J., \& Strimmer, K. (2004). APE: Analyses of phylogenetics and evolutioin in R language. Bioinformatics, 20, 289-290.

Pearse, I. S., \& Altermatt, F. (2013). Predicting novel trophic interactions in a non-native world. Ecology Letters, 16(8), 1088-1094. https://doi. org/10.1111/ele.12143

Peralta, G. (2016). Merging evolutionary history into species interaction networks. Functional Ecology, 30(12), 1917-1925. https://doi. org/10.1111/1365-2435.12669

Peralta, G., Frost, C. M., Rand, T. A., Didham, R. K., \& Tylianakis, J. M. (2014). Complementarity and redundancy of interactions enhance attack rates and spatial stability in host-parasitoid food webs. Ecology, 95(7), 1888-1896. https://doi.org/10.1890/13-1569.1

Peralta, G., Stouffer, D. B., Bringa, E. M., \& Vázquez, D. P. (2020). No such thing as a free lunch: Interaction costs and the structure and stability of mutualistic networks. Oikos, 129(4), 503-511. https://doi. org/10.1111/oik.06503
Peralta, G., Vázquez, D. P., Chacoff, N. P., Lomáscolo, S. B., Perry, G. W., \& Tylianakis, J. M. (2020). Trait matching and phenological overlap increase the spatio-temporal stability and functionality of plant-pollinator interactions. Ecology Letters, 23(7), 1107-1116. https://doi. org/10.1111/ele.13510

Perry, G. L. W., \& Peralta, G. (2020). Data from: Strength of niche processes for species interactions is lower for generalists and exotic species. figshare, https://doi.org/10.17608/k6.auckland.12367685.v2

R Core Team. (2019). R: A language and environment for statistical computing. Vienna, Austria: R Foundation for Statistical Computing. Retrieved from https://www.R-project.org/

Revell, L. J. (2012). phytools: An R package for phylogenetic comparative biology (and other things). Methods in Ecology and Evolution, 3 , 217-223. https://doi.org/10.1111/j.2041-210X.2011.00169.x

Rezende, E. L., Lavabre, J. E., Guimarães, P. R., Jordano, P., \& Bascompte, J. (2007). Non-random coextinctions in phylogenetically structured mutualistic networks. Nature, 448(7156), 925-928.

Robertson, C. J. R., Hyvönen, P., Fraser, M. J., \& Pickard, C. R. (2007). Atlas of bird distribution in New Zealand 1999-2004. Wellington, New Zealand: The Ornithological Society of New Zealand.

Rohr, R. P., Saavedra, S., \& Bascompte, J. (2014). On the structural stability of mutualistic systems. Science, 345(6195), https://doi.org/10.1126/ science.1253497

Sazatornil, F. D., Moré, M., Benitez-Vieyra, S., Cocucci, A. A., Kitching, I. J., Schlumpberger, B. O., ... Amorim, F. W. (2016). Beyond neutral and forbidden links: Morphological matches and the assembly of mutualistic hawkmoth-plant networks. Journal of Animal Ecology, 85 1586-1594. https://doi.org/10.1111/1365-2656.12509

Schleuning, M., Ingmann, L., Strauß, R., Fritz, S. A., Dalsgaard, B. O., Matthias Dehling, D., ... Dormann, C. F. (2014). Ecological, historical and evolutionary determinants of modularity in weighted seed-dispersal networks. Ecology Letters, 17, 454-463. https://doi.org/10.1111/ele.12245

Simmons, B. I., Sutherland, W. J., Dicks, L. V., Albrecht, J., Farwig, N., García, D., ... González-Varo, J. P. (2018). Moving from frugivory to seed dispersal: Incorporating the functional outcomes of interactions in plant-frugivore networks. Journal of Animal Ecology, 87, 995-1007. https://doi.org/10.1111/1365-2656.12831

Thébault, E., \& Fontaine, C. (2010). Stability of ecological communities and the architecture of mutualistic and antagonistic networks. Science, 329, 853-856.

Trøjelsgaard, K., Heleno, R., \& Traveset, A. (2019). Native and alien flower visitors differ in partner fidelity and network integration. Ecology Letters. https://doi.org/10.1111/ele.13287

Tylianakis, J. M., \& Morris, R. J. (2017). Ecological networks across environmental gradients. Annual Review of Ecology, Evolution, and Systematics, 48(1), 25-48. https://doi.org/10.1146/annurev-ecols ys-110316-022821

Vázquez, D. P., \& Aizen, M. A. (2004). Asymmetric specialization: A pervasive feature of plant-pollinator interactions. Ecology, 85(5), 12511257. https://doi.org/10.1890/03-3112

Vázquez, D. P., Chacoff, N. P., \& Cagnolo, L. (2009). Evaluating multiple determinants of the structure of plant-animal mutualistic networks. Ecology, 90(8), 2039-2046. https://doi.org/10.1890/08-1837.1

Vázquez, D. P., Melian, C. J., Williams, N. M., Blüthgen, N., Krasnov, B. R., \& Poulin, R. (2007). Species abundance and asymmetric interaction strength in ecological networks. Oikos, 116(7), 1120-1127. https:// doi.org/10.1111/j.0030-1299.2007.15828.x

Vázquez, D. P., Poulin, R., Krasnov, B. R., \& Shenbrot, G. I. (2005). Species abundance and the distribution of specialization in host-parasite interaction networks. Journal of Animal Ecology, 74(5), 946-955. https://doi.org/10.1111/j.1365-2656.2005.00992.x

Vizentin-Bugoni, J., Maruyama, P. K., \& Sazima, M. (2014). Processes entangling interactions in communities: Forbidden links are more important than abundance in a hummingbird-plant network. Proceedings 
of the Royal Society B: Biological Sciences, 281(1780), https://doi.org/ 10.1098/rspb.2013.2397

Webb, C. O., Ackerly, D. D., \& Kembel, S. W. (2008). Phylocom: Software for the analysis of phylogenetic community structure and trait evolution. Bioinformatics, 24(18), 2098-2100. https://doi.org/10.1093/ bioinformatics/btn358

Webb, C. O., \& Donoghue, M. J. (2005). Phylomatic: Tree assembly for applied phylogenetics. Molecular Ecology Notes, 5(1), 181-183. https://doi.org/10.1111/j.1471-8286.2004.00829.x

Wheelwright, N. T. (1985). Fruit-size, gape width, and the diets of fruiteating birds. Ecology, 66(3), 808-818. https://doi.org/10.2307/1940542

Wikström, N., Savolainen, V., \& Chase, M. W. (2001). Evolution of the angiosperms: Calibrating the family tree. Proceedings of the Royal Society of London. Series B: Biological Sciences, 268(1482), 2211-2220. https://doi.org/10.1098/rspb.2001.1782

Zhang, Q.-G., Buckling, A., \& Godfray, H. C. J. (2009). Quantifying the relative importance of niches and neutrality for coexistence in a model microbial system. Functional Ecology, 23(6), 1139-1147. https://doi. org/10.1111/j.1365-2435.2009.01579.x
Zuur, A. F., leno, E. N., \& Elphick, C. S. (2010). A protocol for data exploration to avoid common statistical problems: Data exploration. Methods in Ecology and Evolution, 1(1), 3-14. https://doi.org/10.1111/ j.2041-210X.2009.00001.x

\section{SUPPORTING INFORMATION}

Additional supporting information may be found online in the Supporting Information section.

How to cite this article: Peralta G, Perry GLW, Vázquez DP, Dehling DM, Tylianakis JM. Strength of niche processes for species interactions is lower for generalists and exotic species. J Anim Ecol. 2020;89:2145-2155. https://doi.org/10.1111/ 1365-2656.13274 